\title{
On Patents, R \& D, and the Stock Market Rate of Return
}

\section{Citation}

Pakes, Ariel. 1985. On patents, R \& D, and the stock market rate of return. Journal of Political Economy 93(2): 390-409.

\section{Published Version}

http://www.jstor.org/stable/1832183

\section{Permanent link}

http://nrs.harvard.edu/urn-3:HUL.InstRepos:3436409

\section{Terms of Use}

This article was downloaded from Harvard University's DASH repository, and is made available under the terms and conditions applicable to Other Posted Material, as set forth at http:// nrs.harvard.edu/urn-3:HUL.InstRepos:dash.current.terms-of-use\#LAA

\section{Share Your Story}

The Harvard community has made this article openly available.

Please share how this access benefits you. Submit a story.

Accessibility 


\section{On Patents, R \& D, and the Stock Market Rate of Return}

\section{Ariel Pakes}

Hebrew University and National Bureau of Economic Research

Empirical work on the causes and effects of inventive activity has had difficulty in finding measures that can indicate when and where changes in either inventive inputs or inventive output have occurred. The recent computerization of the U.S. Patent Office's data base may prove helpful in this context, but there is the problem that a priori we do not know the relationships between patent applications and economically meaningful measures of these inputs and outputs. To help solve this problem, this paper investigates the dynamic relationships among the number of successful patent applications of firms, a measure of the firm's investment in inventive activity (its R \& D expenditures), and an indicator of its inventive output (the stock market value of the firm).

To date our understanding of the role of invention and innovation in economic processes has been severely hampered by a lack of empirical evidence about its causes and its effects. In large part this reflects the difficulty in finding (or constructing) meaningful measures of invention. Early studies often used successful patent applications as their output measure (Schmookler and Brownlee 1962; Griliches and Schmookler 1963; Scherer 1965a, 1965b; Schmookler 1966). The patent variable had the advantage of being a more direct consequence of inventive activity than the other indicators of performance available

This paper is an offshoot of ongoing research with Zvi Griliches and has benefited greatly from discussions with him. I would also like to thank Andrew Abel, Charles Manski, Morris Teubal, an editor, and two referees for helpful comments. John Bound's research assistance is gratefully acknowledged, as is the financial assistance of the NSF (grants PRA79-1379-13740 and SOC79-0479). I, of course, retain sole responsibility for errors. 
(examples used include profits, productivity, and sales of new products) and the advantage that patent applications were, at least in principle, available for an unusually long time period in an extremely detailed breakdown (by both grantee and product class; see U.S. Department of Commerce, Patent and Trademark Office, Office of Technology and Assessment [1973-79]). There were, however, two serious problems with the patent variable. First, though patent counts were available in principle, they were inaccessible in practice. Second, variation in the number of patents granted had no clear interpretation. In particular, though it is clear that patent applications should be granted only when a useful and technologically feasible advance has been made (U.S. Department of Commerce, Patent and Trademark Office 1978) and that the patentee expects some positive benefit from the patent (since the process of application is costly in itself), it is also the case that technological, institutional, and market circumstances can cause patents to vary greatly in their economic value, and that not all useful innovations are patented. (For discussions of the usefulness of patent statistics see the exchange between Kuznets, Sanders, and Schmookler in Nelson [1962]; Comanor and Scherer [1969]; and more recently Taylor and Silberston [1973].)

The recent computerization of the U.S. Patent Office's data base has changed this situation. One can now obtain annual patent applications in a variety of different breakdowns at reasonable cost (see, e.g., Pakes and Griliches 1980). Thus the interpretative problem now takes on renewed importance. That is, in order to use the patent data to investigate hypotheses associated with the inducements to engage in inventive activity, the relationship between inventive inputs and inventive outputs, and the effects of those outputs, we require some understanding of the empirical relationships between patent applications and the investments of patentees, and between those applications and an economically meaningful measure of the value of the inventive outputs the patentees have produced.

This study provides an empirical characterization of the dynamic relationships among the number of successful patent applications of industrial firms, a measure of the firm's investment in inventive activity (its R \& D expenditures), and an indicator of its inventive output (the stock market value of the firm). The use of stock market values as the output indicator has one major advantage in this context. As noted by Arrow (1962), the public-good characteristics of inventive output make it extremely difficult to market. Returns to innovation are earned mostly by embodying it in a tangible good or service that is then sold or traded for other information that can be so embodied (Wilson 1975; von Hippel 1982). There are therefore no direct measures of the value of inventions, while indirect measures of current 
benefits (such as profits or productivity) are likely to react to the output of the firm's research laboratories only slowly and erratically (see the review by Griliches [1979]). On the other hand, under simplifying assumptions, changes in the stock market value of the firm should reflect (possibly with error) changes in the expected discounted present value of the firm's entire uncertain net cash flow stream. Thus, if an event does occur that causes the market to reevaluate the accumulated output of the firm's research laboratories, its full effect on stock market values ought to be recorded immediately. This full effect is, of course, the expected effect of the event on future net cash flows and need not be equal to the effect that actually materializes. The fact that we are measuring expectations rather than realizations, however, does have its advantages. In particular, expectations ought to determine research demand, so that the use of stock market values should allow us to check whether the interpretation we give to our parameter estimates is consistent with the observed behavior of the research expenditure series.

To obtain the implications of such considerations this paper uses a variant of Lucas and Prescott's (1971) investment model, together with a patent indicator function, to suggest restrictions on the stochastic process generating patents, $\mathrm{R} \& \mathrm{D}$, and the stock market rate of return on the firm's equity. These restrictions are embodied in a testable form by approximating both the patent indicator function and the function determining the value of the firm's R \& D program. The resulting econometric model is a variant of the index (Sargent and Sims 1977) or dynamic-factor-analysis (Geweke 1977) models that have recently been used to analyze macroeconomic data. The restrictions imply the existence of a particularly simple recursive system of equations that summarize and interpret the dynamic relationships among patents, $\mathrm{R} \& \mathrm{D}$, and the stock market rate of return.

This recursive form is estimated and tested on a micro data set that contains information on 120 firms over an 8-year period. The restrictions seem to be consistent with the observed behavior of the data, and the paper focuses on the implications of the parameter estimates, particularly those associated with the interpretation of movements in the patent variable. These implications are investigated both in the cross-section dimension (i.e., differences in patent applications between different firms) and in the time-series dimension (differences in the patent applications of a given firm over time).

Section I sets out the framework for the empirical analysis; Section II provides estimates of the recursive form and the associated test statistics. In Section III the implications of the parameter estimates are considered in some detail. Brief concluding remarks close the paper. 


\section{A Framework for the Empirical Analysis}

The econometric model to be investigated consists of equations for the stock market rate of return on the firm's equity, the R \& D expenditures of the firm, and the firm's patent applications. The equations determining $\mathrm{R}$ \& $\mathrm{D}$ expenditures and the stock market rate of return can be motivated by the assumptions that management chooses an $\mathrm{R} \& \mathrm{D}$ program to maximize the expected discounted value of the net cash flows (sales minus current input costs) from its activities and that the stock market measures this expectation subject to error. (Lucas and Prescott [1971] provide a more detailed discussion of similar assumptions.) The properties of the error term in the stock market equation are derived from an arbitrage condition that ensures that agents operating in the stock market cannot make excess returns from a simple linear trading rule and the information contained in the history of the R \& D and stock market rate-of-return series. Patent applications are taken to be an indicator of current and past values of the inputs and the market value of the outputs of the firm's $\mathrm{R} \& \mathrm{D}$ activity. This form of the patent equation reflects the lack of prior information about the nature of the relationships between patents and other variables, and a desire to obtain as general an empirical characterization of those relations as possible. I begin by outlining the derivation of the system of equations to be estimated, focusing on the interpretation of the parameters and the restrictions used to indicate whether this interpretation is consistent with the observed behavior of the data. (More detailed derivations can be found in Pakes [1981].)

Assume that management chooses a research program (a sequence of random variables determining current and future research expenditures, conditional on the information available when those expenditures must be made) to maximize the expected discounted value of the net cash flows from the firm's activities, and that non- $\mathrm{R} \& \mathrm{D}$ inputs can be adjusted costlessly at the beginning of each period to maximize the profits attainable in that period. Management's evaluation of a given program is found by substituting that program into the net cash flow functions, taking the expectation of the expected discounted value of future net cash flows plus current profits conditional on management's current information set $\left(\Omega_{t}\right)$ and subtracting the current cost of the program $\left(\tilde{R}_{t}\right)$ from this expectation. Noting that the current information set, $\Omega_{t}$, will include the past research expenditures of the firm $\left(R_{s}\right.$, for $\left.s<t\right)$ and any other variable known to management at the time input decisions are made that provides information on the distribution of future net cash flows, the value of the program can be written as

$$
V\left(\Omega_{t}, \tilde{R}_{t}\right)=H\left(\tilde{R}_{t}, R_{t-1}, R_{t-2}, \ldots, A_{t}\right)-\tilde{R}_{t},
$$


where $H(\cdot)$ provides the expected discounted value of future net cash flows and current profits conditional on current information, and $A_{t}$ summarizes the effect of other variables that are known to management at the time input decisions are made, but that are not in the econometrician's data set.

Clearly, for a program to be optimal it must maximize $V\left(\Omega_{t}, \tilde{R}_{t}\right)$ with respect to $\tilde{R}_{t}$. That is, if $R_{t}$ is optimal and $V^{*}\left(\Omega_{t}\right)$ is management's evaluation of the firm conditional on optimal behavior, then

$$
V^{*}\left(\Omega_{t}\right)=\max _{\tilde{R}_{t}} V\left(\Omega_{t}, \tilde{R}_{t}\right)=H\left(R_{t}, R_{t-1}, R_{t-2}, \ldots, A_{t}\right)-R_{t} .
$$

Note that equation (2) implies that an assumption on the functional form of $H(\cdot)$ and on the stochastic process generating $\left\{A_{t}\right\}$ will suffice to determine the bivariate stochastic process generating the value of the firm's R \& D program and R \& D itself. This implication is used in the empirical analysis. ${ }^{1}$

If the stock market provided an exact evaluation of the expected discounted value of the firm's future net cash flows conditional on the same information used by management, then the 1-period excess rate of return on the firm's equity (capital gains plus dividends on $\$ 1.00$ invested in the firm minus the interest rate) would equal the percentage increase in the expected discounted value of these net cash flows caused by the information that accumulates over the given period; that is, it would equal $q_{t}^{*}$ where ${ }^{2}$

$$
q_{t}^{*}=\frac{V_{t}^{*}-E\left(V_{t}^{*} \mid \Omega_{t-1}\right)}{V_{t}^{*}} .
$$

We shall allow for a disturbance in the relationship between the observed 1-period rate of return, say $q_{t}$, and $q_{t}^{*}$, that is,

$$
q_{t}=q_{t}^{*}+\eta_{1, t}
$$

\footnotetext{
${ }^{1}$ Equation (2) follows from the Bellman condition for this problem, and the possibility of using it to structure the empirical relationship between investment and the value of the firm is noted by Lucas and Prescott (1971) (see also Sargent 1978, 1979). This procedure does not provide direct evidence about the nature of the relationship between R \& D and net cash flows (a topic of considerable controversy; compare, e.g., Griliches [1979], in which a distributed lag of $R \& D$ is used to construct a knowledge stock that enters into a production function for marketable goods and services, to Nelson and Winter [1982] or Telser [1982], in which the distribution of outcomes from a search process is affected by the quantity of resources invested in research). Our focus here, however, is on the relationships among the value of the firm itself, $R \& D$, and patents; for this the Bellman condition suffices.

${ }^{2}$ This is a discrete-time approximation to a continuous-time result. It assumes that dividends are declared at the beginning of the period and ignores terms equal to the within-period interest earned on dividends per share and the within-period interest on capital gains per share (see Pakes 1981). A correction for this omission did not change the empirical results.
} 
but shall assume that this disturbance is uncorrelated with information that is publicly available at the beginning of the period-in particular, with the history of the $\mathrm{R} \& \mathrm{D}$ and rate-of-return series. This arbitrage condition ensures that the process generating $\eta_{1}$, does not allow agents operating on the stock market to use publicly available information and a simple linear trading rule to make excess returns on that market, and therefore is consistent both with several previous empirical studies (see Fama 1970; LeRoy and Porter 1981) and with the observed behavior of our data (see below). ${ }^{3}$ Since one can ensure that $\operatorname{cov}\left(\eta_{1, t}, q_{i}^{*}\right)=0$ by a normalization that affects only the relative values of coefficients, and therefore does not affect the interpretation of the parameter estimates, we shall also assume this condition in what follows.

The third equation of the model is the indicator function for patent applications. Note that, given current and past R \& D, equation (2) implies that the value of the firm's R \& D program is determined solely by $A_{t}$. To make patents $\left(P_{t}\right)$ an error-ridden indicator of current and past values of the inputs and the outputs from the firm's $\mathrm{R} \& \mathrm{D}$ activity then, it suffices to specify that

$$
P_{t}=P\left(A_{t}, A_{t-1}, \ldots, R_{t}, R_{t-1}, \ldots, G_{t}\right),
$$

where the disturbance process $\left\{G_{t}\right\}$ sets the propensity to patent, that is, determines the number of patents applied for given the history of the inputs and the market value of the outputs from the firm's R \& D activity. The phrase "the propensity to patent" is taken from Scherer $(1965 a, 1965 b)$, who uses it to refer to differences in the number of patents resulting from an innovation of a given quality. We will assume the process generating that propensity, $\left\{G_{t}\right\}$, to be independent of the process generating $\mathrm{R} \& \mathrm{D}$ and the value of the firm. These assumptions provide a precise interpretation for the propensity to patent that will be shown to lead to testable implications below. ${ }^{4}$

\footnotetext{
${ }^{3}$ Note that the presence of the error term, $\eta_{1, l}$, implies that there may be more variance in stock market evaluations than can be justified by the variance in earnings (which accords with the results of LeRoy and Porter [1981] and Shiller [1981]).

${ }^{4}$ Note that eqq. (2) and (5) assume that there is only one sequence of random variables, $\left\{A_{\}}\right\}$, which, given current and past $R$, determines both the value of the $\mathrm{R} \& \mathrm{D}$ program $\left[V^{*}\left(\Omega_{l}\right)\right]$ and, apart from differences in the propensity to patent, patents per se. It is possible to construct a richer model that identifies two factors: one affecting patents only through the R \& D expenditures it induces (say demand shocks) and one having a direct effect on patents and an indirect effect via induced R \& D demand (say technological or supply shocks). For an interesting discussion of the inplications of the differences between demand and supply shocks see Schmookler (1966) and Rosenberg (1974). Since, however, the empirical results indicated that to distinguish between demand and supply shocks one requires more (and quite likely different) data than are used here (see Pakes 1981), and since eq. (5) suffices for the reduced-form interpretation of movements in the patent variable we are after, I shall concentrate on the simpler model, which uses eq. (5), here.
} 
Equations (2), (4), and (5) suggest easily interpretable restrictions on the stochastic process generating $q, R$, and $P$. To derive an explicit form for those restrictions, I use a logarithmic approximation to $H(\cdot)$ in equation (1) and to $P(\cdot)$ in (5); assume that $\left\{a_{t}=\log A_{t}, g_{t}=\log G_{t}\right.$, $\left.\eta_{1, t}\right\}$ evolves as a covariance stationary stochastic process and use its moving average (or Wold) representation (see Anderson 1971, sec. 7.6); and solve equation (2) for $r_{t}=\log R_{t}$, (4) for $q_{t}$, and (5) for $p_{t}=$ $\log P_{t}$. The stochastic process generating $\left\{q_{t}, r_{t}, p_{t}\right\}$ can then be written explicitly as

$$
\begin{aligned}
q_{t} & =\epsilon_{t}+\eta_{1, t}, \\
r_{t} & =\sum_{\tau=0}^{\infty} c_{2, \tau} \epsilon_{t-\tau}, \\
p_{t} & =\sum_{\tau=0}^{\infty} c_{3, \tau} \epsilon_{t-\tau}+\sum_{\tau=0}^{\infty} b_{3, \tau} \eta_{3, t-\tau},
\end{aligned}
$$

where $\left\{\boldsymbol{\epsilon}_{t}\right\},\left\{\eta_{1, t}\right\}$, and $\left\{\eta_{3, t}\right\}$ are three mutually uncorrelated white noise processes (i.e., processes that are serially uncorrelated with constant variance), $a_{t}=\sum_{\tau=0}^{\infty} a_{\tau} \epsilon_{t-\tau}, g_{t}=\sum_{\tau=0}^{\infty} b_{3, \tau} \eta_{3, t-\tau}$, and $b_{3,0}=1$. Equation (6) decomposes the variance in each of the observable deviates (in $q_{t}$, $r_{t}$, and $p_{t}$ ) into portions resulting from current and past values of three innovations (i.e., unpredictable random variables). That is, $\epsilon_{t}$ is the innovation in $a_{t}, \eta_{3, t}$ is the innovation in $g_{t}$, and, due to our arbitrage condition, $\eta_{1, t}$ is an innovation in itself. The three innovations are uncorrelated with past values of all variables and are mutually uncorrelated as a result of the assumed independence of $G_{t}$ from $R_{t}$ and $q_{t}$ and of the definition of $a_{t}{ }^{5}$

For an intuitive understanding of the system in (6), note first that it is realizations of $\epsilon_{t}$ (the process determining $a_{t}$, or the value of the research program) that cause changes in $r_{t}$. Now suppose that an unexpected research-related event occurred during the previous time period that increased the market value of the firm by 1 percent (i.e., $\epsilon$ $=1$ ). The returns on holding the firm's equity over that period will, as a result, be 1 percent above the market rate of return. This same event will also cause changes in the firm's $\mathrm{R} \& \mathrm{D}$ program and in its patent applications. Current $\mathrm{R} \& \mathrm{D}$ expenditures will go up by $c_{2,0}$ percent above what would have been predicted for them at $t-1$ (past €'s can be determined from past $r$ 's), while expected R \& D expenditures $\tau$ periods ahead will go up by $c_{2, \tau}$ percent. Similarly patent appli-

\footnotetext{
${ }^{5}$ The system in (6) ignores any deterministic components in the stochastic process generating $\left\{q_{t}, r_{t}, p_{t}\right\}$. The empirical work adds time dummy variables to all equations, and these should pick up any deterministic components that exist.
} 
cations $\tau$ periods ahead will go up by $c_{3, \tau}$ percent. A realization on $\eta_{1}$ equal to, say, $X$ is noise in the sense that it never (either currently or in the future) affects $p$ or $r$, while a realization of $\eta_{3}=X$ will never affect either research expenditures or the value of the firm and in this sense can be interpreted as a change in the propensity to patent given the inputs and the outputs of the firm's R \& D activities.

\section{Test Statistics and Parameter Estimates}

Formally the econometric model given by equation (6) is a restricted version of a dynamic-factor-analysis (Geweke 1977) or an unobservable index (Sargent and Sims 1977) model. The name is a result of the fact that in (6) there is a single stochastic process, built up from the $\epsilon$, that accounts for all the observed correlations between current and past values of the components of $y_{t}=\left(q_{t}, r_{t}, p_{t}\right)$. This provides the empirical interpretation to realizations of $\eta_{3}$ and $\eta_{1} ; \eta_{3}$ stems from differences in patenting that are never associated with differences in the value of the firm or in the firm's R \& D program; and $\eta_{1}$ stems from movements in the stock market value of the firm that are never associated with its R \& D program or its patents. The model in equation (6) is more restricted than the general index model. In particular, it constrains $q_{t}$ to be a function of only current values of $\epsilon$ and $\eta_{1}$. Since the history of $\epsilon$ and $\eta_{1}$ can be predicted from the history of $y$, the implication this constraint is testing is that realizations of $q_{t}$ cannot be predicted from the history of the variables in our data set. In addition the system in (6) does not allow a separate stochastic process that affects $r$ but does not affect $p$ or $q$ (all the variance in $r$ is accounted for by current and past values of $\epsilon$, or there is no measurement error in $r$ ). This assumption was maintained because the empirical results indicated that there was no need to allow for such a measurement error. ${ }^{6}$

The restrictions embodied in (6) allow for relatively straightforward estimation and testing procedures. This results from the fact that the system in (6) has a recursive form, in which all restrictions are exclusion restrictions, and which, by its recursive nature, permits equation-by-equation estimation techniques. This recursive form has $q_{t}$ as a function of the history of $y_{t}, r_{t}$ as a function of $q_{t}$ and the history of $y_{t}$, and $p_{t}$ as a function of $q_{t}, r_{t}$, and the history of $y_{t}$. We now provide and estimate each of the equations of this recursive form.

\footnotetext{
${ }^{6}$ See Pakes (1981). This finding is comforting in a slightly different context, since it indicates that once one moves away from measuring the effects of $R \& D$ via its impact on indirect measures of current benefits, there is less need to worry about measurement error in the R \& D series (see Griliches [1979] for the importance of measurement error in studies designed to measure the contribution of $\mathrm{R} \& \mathrm{D}$ to productivity).
} 
TABLE 1

Tests of the Unpredictability of $q_{t}$ : Test Statistics for Joint Significance

\begin{tabular}{|c|c|c|c|c|}
\hline \multirow[b]{2}{*}{$\begin{array}{l}\text { Four LAGGed } \\
\text { Values OF: }\end{array}$} & \multirow[b]{2}{*}{$\begin{array}{c}\text { Test } \\
\text { Statistic }\end{array}$} & \multicolumn{3}{|c|}{ INCLUDED IN THE EQUATION: } \\
\hline & & $\begin{array}{c}q \\
(1)\end{array}$ & $\begin{array}{l}r, p \\
(2)\end{array}$ & $\begin{array}{c}q, r, p \\
(3)\end{array}$ \\
\hline$q$ & $F^{4}$ & $.11 *$ & n.i. & $.44^{*}$ \\
\hline$r$ & $F^{4}$ & n.i. & $1.82 *$ & $2.00 *$ \\
\hline$p$ & $F^{4}$ & n.i. & $.40 *$ & $.32 *$ \\
\hline$r, p$ & $F^{8}$ & n.r. & $1.49 \dagger$ & $1.56 \dagger$ \\
\hline$r, p, q$ & $F^{12}$ & n.r. & n.r. & $1.09 \ddagger$ \\
\hline
\end{tabular}

Note.- There are 480 observations ( 120 firms over 4 years). Time dummies are included in all equations. "Not included" and "not relevant" are denoted n.i. and n.r.

* Critical values are 2.39 and 3.36 at 5 and 1 percent, respectively.

$\dagger$ Critical values are 1.96 and 2.55 at 5 and 1 percent, respectively.

$\ddagger$ Critical values are 1.78 and 2.23 at 5 and 1 percent, respectively.

The data used here contain the successful patent applications, the $\mathrm{R} \& \mathrm{D}$ expenditures, and the annual rates of return on the stocks of 120 firms over an 8-year period (1968-75). The sample of firms and the method of constructing the patent and $\mathrm{R} \& \mathrm{D}$ variables are discussed in Pakes and Griliches (1984). The observations on the stock market rates of return were taken from the 1975 Master File of the University of Chicago's Center for Research in Security Prices (CRSP). I use the rates of return in the year before the $\mathrm{R} \& \mathrm{D}$ expenditures and patent applications were made. This is a result of the assumption that decisions on $r$ and $p$ are made at the beginning of the year; as we shall see below, this assumption is supported by the data.

The leading equation of the recursive form has $q$ as a function of lagged values of itself, $r$, and $p$. The model predicts that neither component of $q\left(\epsilon\right.$ or $\left.\eta_{1}\right)$ can be predicted by a linear combination of these variables, or that agents cannot make excess returns on the stock market from a linear trading rule based on the history of $y_{t}$. Table 1 presents test statistics for this hypothesis. Column 1 shows that it is reasonable to assume that $q_{t}$ cannot be predicted from past values of itself, column 2 that it cannot be predicted from past values of $r$ or $p$, and column 3 that it cannot be predicted from past values of itself, $r$, or $p$. Thus rates of return do seem to represent unpredictable movements in the value of the firm, or at least movements that cannot be predicted with the variables in our data set.

To obtain the recursive form of the $r_{t}$ equation, first note that $\epsilon_{t}$ can be written as

$$
\epsilon_{t}=\theta q_{t}+v_{t},
$$

where $\theta=\sigma_{\epsilon}^{2} / \sigma_{q}^{2}$; that is, $\theta$ is the signal-to-total-variance ratio in $q$, and $v_{t}=(1-\theta) \epsilon_{t}-\theta \eta_{1, t}$. It follows that $v_{t}$ is uncorrelated with $q_{t}$ and with 
past values of all variables. Next, assuming that there is an autoregressive representation for the $r_{t}$ equation, we obtain it as $r_{t}=c_{2,0} \epsilon_{t}+$ $d_{2}(L) r_{t-1}$, where, here and in the discussion below, a function of $L$ represents a polynomial in the lag operator and $c_{2}(L)=c_{2,0}[1-$ $\left.d_{2}(L)\right]^{-1} \cdot{ }^{7}$ Substituting (7) into the autoregressive form of the $r_{t}$ equation, we obtain

$$
r_{t}=c_{2,0} \theta q_{t}+d_{2}(L) r_{t-1}+c_{2,0} v_{t} .
$$

Note that the variance of the disturbance in equation (8) is $\sigma_{q}^{2} c_{2,0}^{2}(1$ $-\theta) \theta$, so that (together with the first coefficient and $\sigma_{q}^{2}$ ) it can be used to identify $\theta$ and therefore $c_{2,0}$.

Equation (8) is reminiscent of Grunfeld's (1960) investment equation. Grunfeld used stock market evaluations to proxy for the effect of unobservable expectations on investment (Lucas and Prescott [1971] provide a more rigorous justification for this procedure). In equation (8) revisions in stock market evaluations (i.e., $q_{t}$ ) are used to proxy for the effect of factors that caused revisions in the expected discounted value of the firm's R \& D program. This allows us to identify the time pattern of the relationship among changes in the market value of the firm's R \& D program, patents, and R \& D itself. Note also that since $v_{t}$ is uncorrelated with $q_{t}$ and with past values of all variables, equation (8) implies that in a regression of $r_{t}$ on $q_{t}$ and lagged values of all variables (which, recall, is the second equation of the recursive form), all the coefficients but those on current $q$ and lagged $r$ should be close to zero.

The recursive form of the $p_{t}$ equation is obtained by multiplying the last equation in the system in (6) through by $b_{3}(L)^{-1}=1-d_{3}(L)$ and making the substitution $\epsilon_{t}=c_{2}(L)^{-1} r_{t}$. This implies that

$$
p_{t}=\gamma(L) r_{t}+d_{3}(L) p_{t-1}+\eta_{3, t},
$$

where $\gamma(L)=c_{3}(L) c_{2}(L)^{-1}\left[1-d_{3}(L)\right]$. Since $\eta_{3, \ell}$ is uncorrelated with current $q$ and $r$ and past values of all variables, the model implies that in a regression of $p_{t}$ on $q_{t}, r_{t}$, and lagged values of all variables (which is the last equation of the recursive form), all the $q$ coefficients should be close to zero.

Table 2 presents the results. The unrestricted autoregressive forms of these equations (the form that has $r$ and $p$ as a function of only lagged values of all variables) have been presented for comparison, while the relevant test statistics are presented at the bottom of the

7 That is, $d_{2}(L)=\sum_{\tau=0}^{\infty} d_{2, \tau} L^{\tau}$, where $L^{k} x_{t}=x_{t-k}$. I assume that the roots of the polynomial equations associated with $c_{2}(L)$ and $b_{3}(L)$ all lie outside the unit circle. This ensures the existence of a convergent autoregressive representation for the $r_{l}$ and $p$, equations (see Anderson 1971, sec. 5.7). 


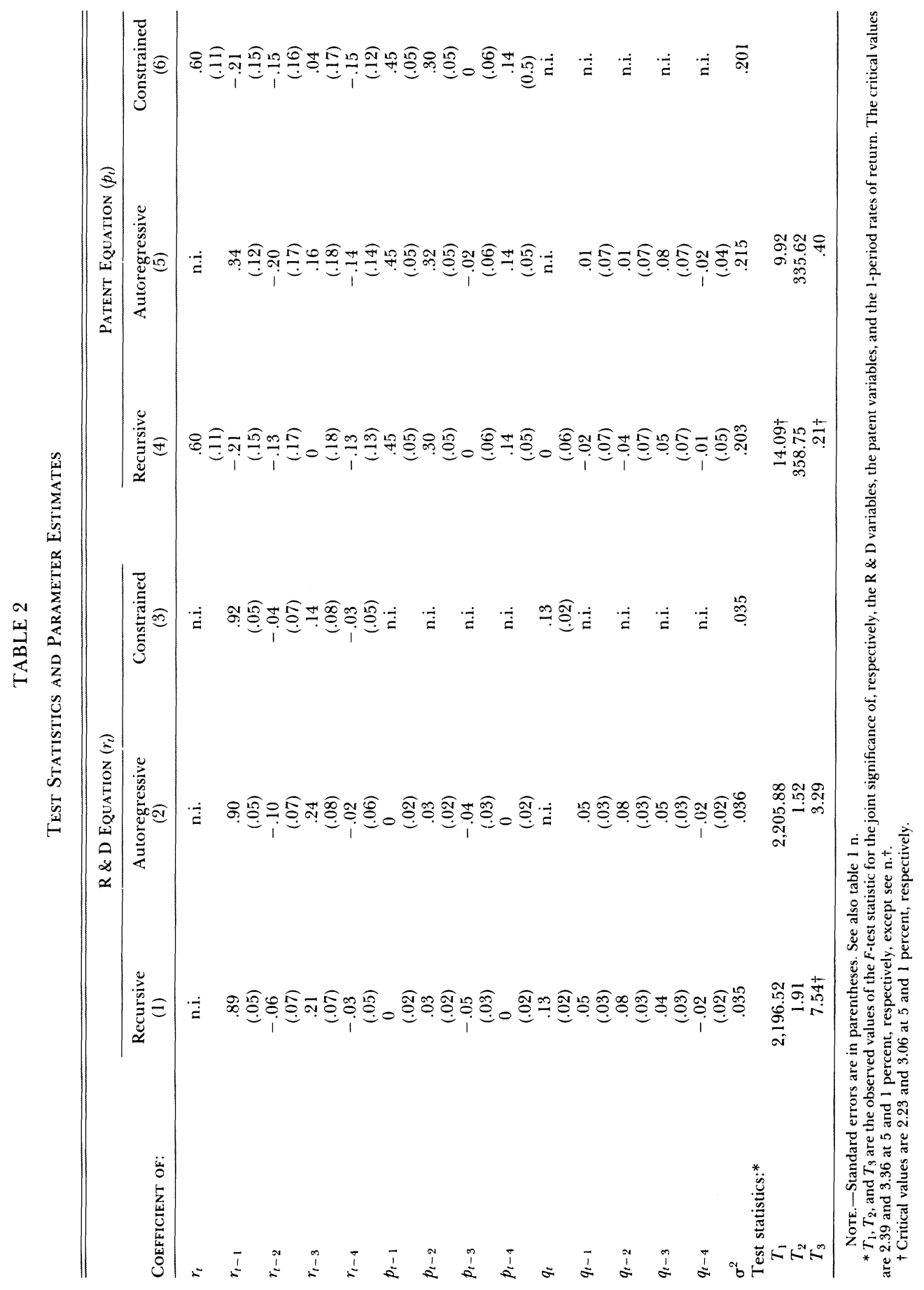


table. Beginning with the $\mathrm{R} \& \mathrm{D}$ equation (col. 1) one finds two rather striking implications of the estimates. First, the events leading the market to reevaluate the firm are indeed highly and positively correlated with the events leading the firm to change its $\mathrm{R} \& \mathrm{D}$ policy from what would have been predicted given the firm's observable history (i.e., the history of $y_{t}$ ). There is really no doubt on this point, as the coefficient of $q_{t}$ is large and estimated with great precision. Equally striking is the fact that we can be quite sure that each of the coefficients of the lagged $p$ variables in this equation is very close to zero (once again all of the estimates are near zero and their standard errors are small; see also test $T_{2}$ of this col.). Thus once we account for the influence of past $r$ and current and past $q$, the additional information in movements in past $p$ is information that never affects $R \& D$ expenditures. This is confirmation of our interpretation of the $\eta_{3, t}$ process as differences in the propensity to patent for a given history of the firm's $\mathrm{R} \& \mathrm{D}$ program, since changes in it do not affect $r$.

The only implication of the model, then, that is not strongly supported by the estimates of column 1 is the zero restriction on the lagged $q$ coefficients. The relevant test statistic here is $T_{3}$ of column 2, which is significant at the 5 percent but not the 1 percent level. Additional results, which will not be discussed here, indicated that we observe marginally significant lagged $q$ coefficients because the assumption that the process generating $r_{t}$ has a low-order autoregressive representation is questionable. Since this is a technical problem and since correcting for it did not change any of the basic implications of the parameter estimates, we shall ignore it below and accept the column 3 estimates for the $r_{t}$ equation. ${ }^{8}$

The parameter estimates from the patent equation make it clear that current and past changes in $\mathrm{R} \& \mathrm{D}$ (past changes only in col. 5) have a significant effect on changes in current patent applications (test $T_{1}$ ). Though this was perhaps to be expected (see Pakes and Griliches 1980), what is more surprising is that once the effect of $\mathrm{R} \& \mathrm{D}$ expenditures on patent applications is taken care of, other factors leading to a change in the market's evaluation of the firm are not correlated with patent applications (test $T_{3}$ ). In particular, all the $q$ coefficients in the $p$ equation are near zero, and this leads us to accept the interpretation of the error in the regression of $p_{t}$ on the $r_{t-\tau}$ as differences in the propensity to patent, given the market value of the output of the firm's current and past research expenditures.

An omnibus test of the model's restrictions can be obtained by comparing the likelihoods of the restricted and the unrestricted recursive system of equations. The observed value of the $\chi_{25}^{2} / 25$ likeli-

\footnotetext{
${ }^{8}$ More details on these points can be found in Pakes (1981).
} 
hood ratio test statistic for the null hypothesis embodied in the model's assumptions was 1.15, which is not too different from the expected value of $\chi_{25}^{2} / 25$ deviate $(0.97)$ and certainly not surprising (the 5 percent critical test value is 1.51 ). Since the assumptions of the model seem to be consistent with the observed behavior of the data, ${ }^{9}$ we now go on to explore the implications of the parameter estimates in greater detail.

\section{Some Implications of the Parameter Estimates}

I begin with the implications of the estimates for the interpretation of movements in $q$ and $r$. Noting that $\sigma_{q}^{2}=0.10$ and using the parameters of the R \& D equation, we find a $\theta\left(\sigma_{\epsilon}^{2} / \sigma_{q}^{2}\right)$ of 0.05 . That is, about 5 percent of the within-period variance in the rate of return is caused by events that also cause changes in both $\mathrm{R} \& \mathrm{D}$ expenditures and patent applications. ${ }^{10} \mathrm{~A} \theta$ of 0.05 implies that $c_{2,0}\left(=\partial r_{t} / \partial \epsilon_{t}\right)=2.60$. This implies that a 1 percent increase in $\mathrm{R} \& \mathrm{D}$ expenditures above what would have been predicted from past information is associated with events that have caused an increase in the value of the firm of 0.39 percent. Evaluating derivatives at the means of all variables, we find that a $\$ 100$ unexpected increase in $\mathrm{R} \& \mathrm{D}$ is associated with research and patent-related events that have increased the value of the firm by $\$ 1,870 .{ }^{11}$ Recall that the results implied that there was no need to allow for measurement error in R \& D (see Sec. II), so that all unpredictable changes in $\mathrm{R} \& \mathrm{D}$ have this interpretation. The unexpected increase in patents is $c_{3,0} \epsilon_{t}+\eta_{3, t}$, where, from the estimates, $c_{3,0}=1.56$. Thus, events that lead to a unit increase in $\epsilon$ result in a 1.56 percent increase in successful patent applications. Much of the variance in the unexpected change in the patent variable (about 94

\footnotetext{
${ }^{9}$ To ensure the robustness of this conclusion with respect to the statistical assumptions, the tests of the recursive form were also run, using first differences (instead of levels) of the $r$ and $p$ series, using weighted $r$ and $p$ series where the weight for a given firm was the square root of the mean $\mathrm{R} \& \mathrm{D}$ expenditures of that firm over the sample period, and allowing the coefficients of the recursive form to differ in the different years of the sample. None of the resulting test statistics indicated rejection of the model's assumptions. There was, however, an indication that some of the coefficients in the recursive form were not stable over time, though the economic implications of the intertemporal differences in these coefficients were minor.

${ }^{10}$ The firms in our sample are all rather large (the average value of their common shares is $\$ 1,514$ million) and diversified, and they do a great deal of research.

${ }^{11}$ The means reported here are sample means; i.e., they are calculated over all observations ( $N$ firms and $T$ years) and thus require the use of price deflators. The CPI was used to deflate stock market values, and the R \& D deflator discussed in Pakes and Griliches (1984) was used for R \& D expenditures. The base year for these deflators is 1972, so all dollar figures in the text are in 1972 dollars.
} 


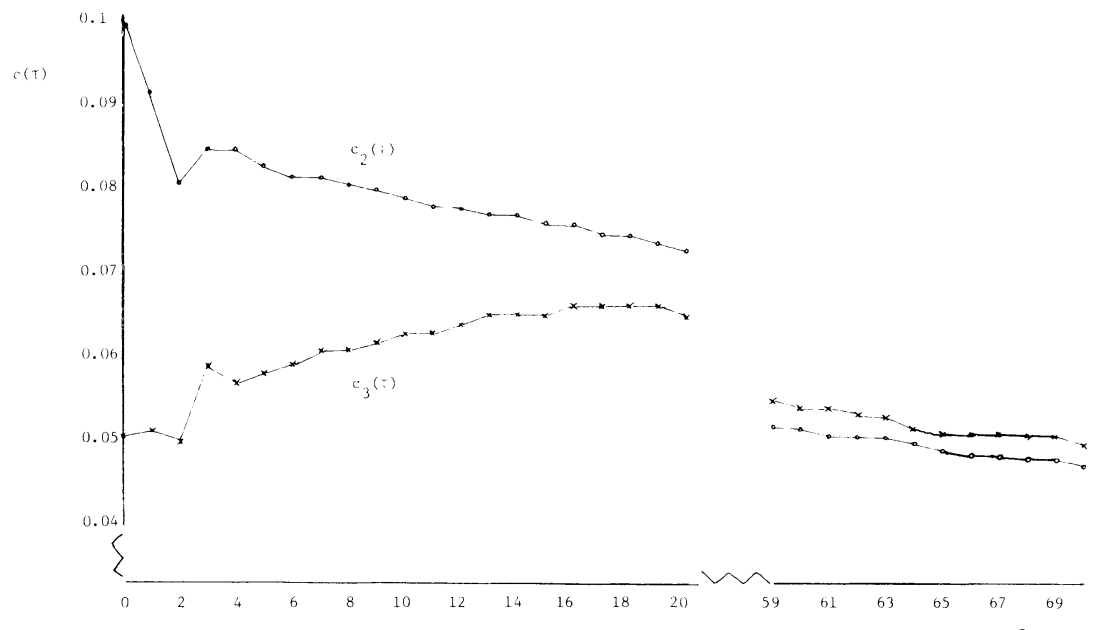

FIG. 1.-The distributed lag from $\epsilon$ to $r\left[c_{2}(\tau)\right]$ and from $\epsilon$ to $p\left[c_{3}(\tau)\right]$

percent) is noise, so that we find that a 1 percent increase in patents will, again on average, reflect only a 0.044 percent increase in the market value of the firm; alternatively, one additional patent indicates that events have occurred that increase the firm's market value by $\$ 810,000$. The estimates imply, then, that although unexpected changes in patents are a very noisy indicator of unexpected changes in the market value of the firm's $\mathrm{R} \& \mathrm{D}$ program, on average, an increase of one patent is associated with large changes in market value.

Figure 1 presents the estimates of the distributed lags from $\epsilon$ to $r$ (labeled $\left.c_{2}[\tau]\right)$ and from $\epsilon$ to $p\left(c_{3}[\tau]\right)$; while figure 2 presents the distributed lags from $r$ to $p\left(\gamma^{*}[\tau]\right.$, where $\left.\gamma^{*}[\tau]=c_{3}[\tau] c_{2}[\tau]^{-1}\right)$ and from $\eta_{3}$ to $p\left(b_{3}[\tau]\right)$. Figure 1 makes it clear that the events that change the market value of a firm's research program have a persistent effect on both patents and $\mathrm{R} \& \mathrm{D}$ expenditures. As a result interfirm differences in $\mathrm{R} \& \mathrm{D}$ expenditures are quite stable over time, and if we are seeking their causes we should look for factors in the firm's environment whose effects are likely to persist. On the other hand, the small changes that do occur in the firm's $\mathrm{R} \& \mathrm{D}$ expenditures are almost entirely determined by recent events. Thus events that occurred over 3 years earlier will have essentially the same effect on $r_{t}$ as on $r_{t-1}$ and cannot cause differences between them. The estimate of $c_{3}(\tau)$ is similar to that of $c_{2}(\tau)$, except that the effect of the $\epsilon$ on $p$ tends to increase before declining, giving the impression that $p$ reacts to the $\epsilon$ a little more slowly than $r$ does. Thus, moving to figure 2 , we see that patent 


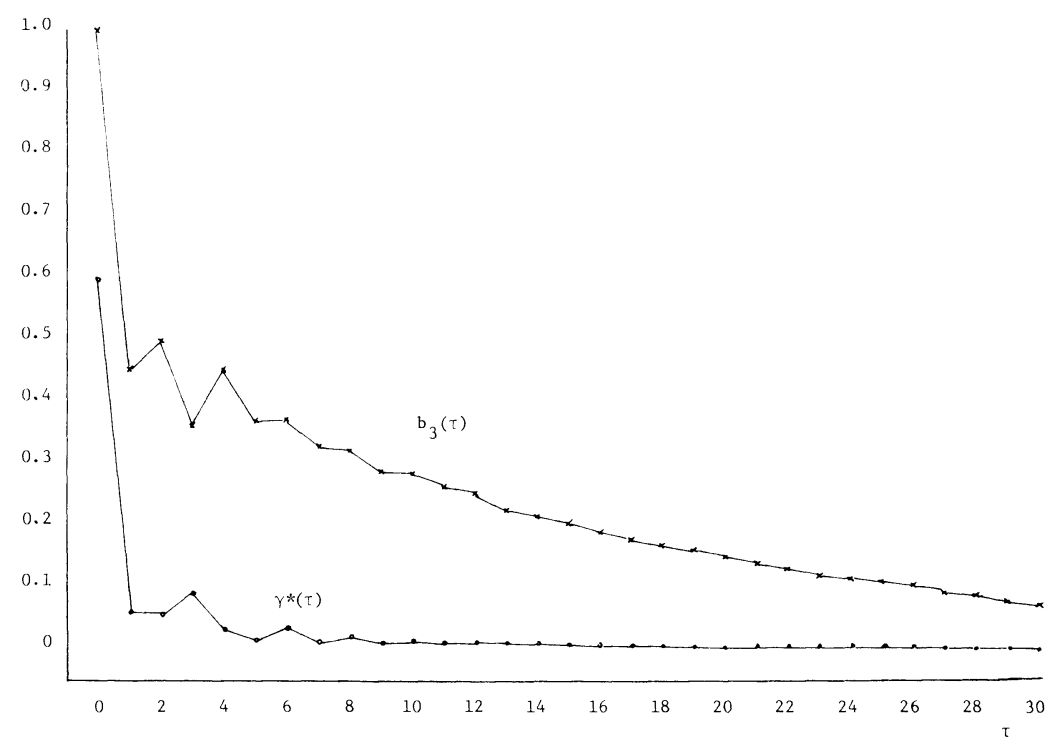

FIG. 2.- The distributed lag from $r$ to $p\left[\gamma^{*}(\tau)\right]=\left[c_{3}(\tau) c_{2}(\tau)^{-1}\right]$ and from $\eta_{3}$ to $p$ $\left[b_{3}(\tau)\right]$.

applications follow the factors determining the productivity of current R \& D expenditures (and hence R \& D demand) quite closely.

The sum of the coefficients in the distributed lag from $r$ to $p$ is 1.18 , implying that the events leading to a 1 percent increase in $\mathrm{R} \& \mathrm{D}$ expenditures will, eventually, lead to a 1.18 percent increase in patented innovations. About 50 percent of these patents will be applied for in the same year as the $\mathrm{R} \& \mathrm{D}$ expenditures are incurred, while 70 percent will be applied for within 3 years. In fact, if from $c_{2}(\tau)$ one gets the impression that events that cause unexpected changes in the value of a firm's $\mathrm{R} \& \mathrm{D}$ program start a chain reaction leading to more $\mathrm{R} \& \mathrm{D}$ expenditures far into the future, then $\gamma^{*}(\tau)$ seems to be describing a situation where firms patent around the links of this chain almost as quickly as they are completed. There is also a long, slim tail of the distributed lag from $r$ to $p$, which probably represents the effect of the basic research done in the past on current patented innovations. ${ }^{12}$

${ }^{12}$ The reader is cautioned not to interpret the distributed lag from $\mathrm{R} \& \mathrm{D}$ to patents as representing a production-type relationship between past $\mathrm{R} \& \mathrm{D}$ and patentable output. The estimates presented here do not distinguish the direct effect of R \& D on patents from the effect of changes in the value of the firm's R \& D program (in $a_{t}$ ) on $\mathrm{R} \& \mathrm{D}$ and patents (this is the dynamic analogue of the classical simultaneous equations problem discussed in Marschak and Andrews [1944]). The estimate of $\gamma^{*}(L)$ is similar 
The estimates of $g(\tau)$ indicate that interfirm differences in the propensity to patent are not as stable over time as one might have expected. Thus, recalling that $g_{t}$ is the propensity to patent $\left(g_{t}=\sum_{\tau=0}^{\infty}\right.$ $b_{3, \tau} \eta_{3, t-\tau}$ ) we find that the correlation of $g_{t}$ and $g_{t-\tau}$ is only about .75 for $\tau=1$, going down to around .6 for $\tau=2,3$, and 4, and decaying at a fairly constant rate of .9 thereafter.

A question of general interest is: How closely related to differences in the outputs and the inputs of the firm's inventive activity are measures based on the recently computerized U.S. Patent Office's data base likely to be? The data suggest that some differences in patent applications are close approximations to differences in these variables, while others are not.

First, consider constructing a cross section of patent applications by firm in order to study the causes of interfirm differences in inventive output (or their effects). The estimates indicate that 76 percent of the interfirm variance in patents is caused by the $\epsilon_{t}$, that is, by researchrelated events that cause changes in the market value of the firm, while the remainder is noise (not related to either the firm's research program or its value). If one were to ask what proportion of the variance in $p_{t}$ is caused by the events determining current research demand, the answer would be a little less, but not much. To see this, consider the projection of $p_{t}$ onto $r_{t}$, that is, $p_{t}=\phi r_{t}+g_{t}^{\prime}$, where $\operatorname{cov}\left(g_{t}^{\prime}, r_{t}\right)=0 .{ }^{13}$ Appropriate calculations indicate that $\phi=1.12$, while $\operatorname{var}\left(\phi r_{t}\right) / \operatorname{var}\left(p_{t}\right)=0.74$. A 1 percent difference in $R_{t}$ will, therefore, be associated with a 1.12 percent difference in patent applications, while about 74 percent of the interfirm variance in $p_{t}$ can be attributed to interfirm variance in $r_{t}$. Inverting these calculations one finds that, on average, a 1 percent difference in current patent applications is associated with factors that have led to a 0.66 percent difference in $R_{t} ;{ }^{14}$ this implies that (on evaluating derivatives at the sample means of all variables), a difference of one patent is associated with events that, on average, are associated with a $\$ 304,000$ difference in current R \& D activity.

Unfortunately, intrafirm differences in patent applications do not seem to be as good an indicator of intrafirm differences in inventive output as interfirm differences. The proportion of the variance in $p_{i t}$ - $p_{i t-1}$ caused by the $\epsilon$ is about 8 percent, with 45 percent of this 8 percent caused by research-related and patent-related events that changed the market value of the firm in the given period (by $\epsilon_{t}$ ).

to what Zvi Griliches and I, in joint preliminary work, suggest as a likely form for this lag structure (Pakes and Griliches 1980).

${ }^{93}$ Here $\phi=\Sigma c_{r r}(\tau) \gamma^{*}(\tau) / c_{r r}(0)$, where $c_{r r}(\tau)=\operatorname{cov}\left(r_{t}, r_{t-\tau}\right)$ and $\gamma^{*}(\tau)$ is the th lag coefficient in the distributed lag from $r$ to $p$.

${ }^{14}$ That is, $r_{\imath}=\phi^{\prime} p_{\imath}+g_{\imath}^{\prime \prime}$, where $\operatorname{cov}\left(g_{\imath}^{\prime \prime}, p_{\imath}\right)=0$, and $\phi^{\prime}=0.66$. 
These ratios do, however, increase significantly when one takes intrafirm differences in patent applications that are farther apart. The proportion of the variance in $p_{i t}-p_{i t-5}$ caused by the $\epsilon$ is 15 percent, with over 75 percent caused by events that occurred during the 5-year period. For 10-year differences the figures move to over 20 and 85 percent, respectively. Thus if one were to use intrafirm differences in patent applications to study the effect of changes in a firm's inventive output on, say, its investment policy or its share of a given market, then one ought, probably, to stick to longer-term changes in all variables.

\section{Concluding Remarks}

Empirical work on the causes and the effects of inventive activity has had difficulty in finding variables that can indicate when and where changes have occurred either in the inducements to invest in inventive activity or in inventive output. The recent computerization of the U.S. Patent Office's data base may provide some help in this context, but there is the problem that a priori one does not know the relationship between successful patent applications and economically meaningful measures of these inputs and outputs. To provide a partial answer to this question, this paper investigated the relationship between successful patent applications, a measure of the inputs into the inventive process ( $\mathrm{R} \& \mathrm{D}$ expenditures), and a variable that provides a measure of, among other diverse factors, the value of the output from this process (movements in the stock market value of the firm's equity). The assumptions that management chooses an $\mathrm{R} \& \mathrm{D}$ program to maximize the expected discounted value of the net cash flows from the firm's activities, that the stock market measures this expectation subject to error, and that patents are an error-ridden measure of current and past values of the inputs to and the outputs from the firm's R \& D activity were used to suggest a testable interpretation of the dynamic relationships among the three observable variables. This interpretation seemed consistent with the observed behavior of the data, and the qualitative nature of the empirical results can be summarized quite succinctly.

First, it is clear that the events that lead the market to reevaluate the firm are indeed significantly correlated with unpredictable changes in both the R \& D and the patents of the firm. Moreover, the estimates imply that, on average, unexpected changes in patents and in $\mathrm{R} \& \mathrm{D}$ are associated with quite large changes in the market value of the firm. Nevertheless, there is a large variance to the increases in the value of the firm that are associated with a given increase in its patents. This may reflect an extremely dispersed distribution of the 
values of patented ideas. Further, most of the variance in the stock market rate of return has little to do with the firm's inventive endeavors, at least as measured by its R \& D input and its patent output. However, once appropriate disturbances are allowed for, the observations on the stock market rate of return do seem to enable us to separate out the time pattern of the impacts of events that cause changes in the value of a firm's $\mathrm{R} \& \mathrm{D}$ program (movements in the stock market rate of return do seem to be a result of unpredictable events, and stock market evaluations should not depend on the long and erratic lag structure between invention and the current benefits derived from it).

The events that do cause the market to reevaluate the firm's inventive endeavors have long-lasting effects on both the patents and R \& D expenditures of the firm. On the other hand, the effects of the factors that cause differences in the propensity to patent are much more transient. These timing patterns have several implications. The large differences in the patent applications of different firms are mostly associated with differences in the market's evaluations of differences in the firms' inventive output. However, the smaller differences that occur in the patent applications of a given firm over time are due largely to differences in the propensity to patent. Of course, some information is still in the time-series dimension. If we were to observe, for example, a sudden burst in the patent applications of a given firm, we could be quite sure that events have occurred to cause a large change in the market value of its R \& D program; but smaller changes in the patent applications of a given firm are not likely to be very informative. This latter statement must be modified somewhat when we consider long-term differences in the patents of a given firm (say differences over a 5- or 10-year interval), as a larger portion of their variance is caused by events that lead the market to reevaluate the firm's inventive output during these periods.

The timing of the impact of the events that cause unexpected changes in the market value of a firm's inventive activity on patents is very close to the timing of their impact on $R \& D$. In fact one gets the impression from the estimates that an event that causes a 1 percent change in the market value of a firm's inventive activity starts a chain reaction leading to more $\mathrm{R} \& \mathrm{D}$ expenditures far into the future, with the firm patenting around the links of this chain almost as soon as they are completed. These timing patterns imply that current patent applications are highly correlated with current R \& D demand. In this context it should be noted that $\mathrm{R} \& \mathrm{D}$ itself is generally not available by product field, for smaller business concerns or, before 1972, for most large business enterprises. The availability of the patent data together with some of the qualitative results presented here should, 
therefore, allow us to study the causes and effects of R \& D activity in a much wider variety of situations, and in more detail, than has been possible to date. To use patent and $\mathrm{R} \& \mathrm{D}$ data jointly to distinguish between the different kinds of events that can cause changes in inventive activity (say demand shocks vs. technological or supply shocks), and then isolate their impacts on behavior and performance, seems to require a larger, and perhaps more detailed, model than the one used here.

\section{References}

Anderson, Theodore W. The Statistical Analysis of Time Series. New York: Wiley, 1971.

Arrow, Kenneth J. "Economic Welfare and the Allocation of Resources for Invention." In The Rate and Direction of Inventive Activity: Economic and Social Factors, edited by Richard R. Nelson. Univ.-Nat. Bur. Conf. Ser., no. 13. Princeton, N.J.: Princeton Univ. Press (for N.B.E.R.), 1962.

$\rightarrow$ Comanor, William S., and Scherer, Frederic M. "Patent Statistics as a Measure of Technical Change." J.P.E. 77 (May/June 1969): 392-98.

Fama, Eugene F. "Efficient Capital Markets: A Review of Theory and Empirical Work." J. Finance 25 (May 1970): 383-417.

Geweke, John. "The Dynamic Factor Analysis of Economic Time-Series Models." In Latent Variables in Socio-Economic Models, edited by Dennis J. Aigner and Arthur S. Goldberger. Amsterdam: North-Holland, 1977.

Griliches, Zvi. "Issues in Assessing the Contribution of Research and Development to Productivity Growth." Bell J. Econ. 10 (Spring 1979): 92-116.

Griliches, Zvi, and Schmookler, Jacob. "Inventing and Maximizing." A.E.R. 53 (September 1963): 725-29.

Grunfeld, Yehuda. "The Determinants of Corporate Investment." In The Demand for Durable Goods, edited by Arnold C. Harberger. Chicago: Univ. Chicago Press, 1960.

LeRoy, Stephen F., and Porter, Richard D. "The Present-Value Relation: Tests Based on Implied Variance Bounds." Econometrica 49 (May 1981): 555-74.

Lucas, Robert E., Jr., and Prescott, Edward C. "Investment under Uncertainty." Econometrica 39 (September 1971): 659-81.

Marschak, Jacob, and Andrews, William H., Jr. "Random Simultaneous Equations and the Theory of Production." Econometrica 12 (July-October 1944): 143-205.

Nelson, Richard R., ed. The Rate and Direction of Inventive Activity: Economic and Social Factors. Univ.-Nat. Bur. Conf. Ser., no. 13 Princeton, N.J.: Princeton Univ. Press (for N.B.E.R.), 1962.

Nelson, Richard R., and Winter, Sidney G. An Evolutionary Theory of Economic Change. Cambridge, Mass.: Harvard Univ. Press, 1982.

Pakes, Ariel. "Patents, R \& D, and the Stock Market Rate of Return." Working Paper no. 786. Cambridge, Mass.: N.B.E.R., 1981.

Pakes, Ariel, and Griliches, Zvi. "Patents and R \& D at the Firm Level: A First Report.” Econ. Letters 5, no. 4 (1980): 377-81.

- . "Patents and R \& D at the Firm level: A First Look." In $R \in D$, Patents, and Productivity, edited by Zvi Griliches. Chicago: Univ. Chicago Press, 1984. 
Rosenberg, Nathan. "Science, Invention, and Economic Growth." Econ. J. 84 (March 1974): 90-108.

$\rightarrow$ Sargent, Thomas J. "Estimation of Dynamic Labor Demand Schedules under Rational Expectations.” J.P.E. 86 (December 1978): 1009-44.

- Macroeconomic Theory. New York: Academic Press, 1979.

Sargent, Thomas J., and Sims, Christopher A. "Business Cycle Modelling without Pretending to Have Too Much A Priori Economic Theory." In New Methods in Business Cycle Research: Proceedings from a Conference, edited by Christopher A. Sims. Minneapolis: Fed. Reserve Bank Minneapolis, 1977.

$\rightarrow$ Scherer, Frederic M. "Corporate Inventive Output, Profits, and Growth." J.P.E. 73 (June 1965): 290-97. (a)

- "Firm Size, Market Structure, Opportunity, and the Output of Patented Inventions." A.E.R. 55 (December 1965): 1097-1125. (b)

Schmookler, Jacob. Invention and Economic Growth. Cambridge, Mass.: Harvard Univ. Press, 1966.

$\rightarrow$ Schmookler, Jacob, and Brownlee, Oswald H. "Determinants of Inventive Activity." A.E.R. Papers and Proc. 52 (May 1962): 165-76.

$\rightarrow$ Shiller, Robert J. "Do Stock Prices Move Too Much to Be Justified by Subsequent Changes in Dividends?" A.E.R. 71 (June 1981): 421-36.

Taylor, Christopher T., and Silberston, Z. A. The Economic Impact of the Patent System: A Study of the British Experience. Cambridge: Cambridge Univ. Press, 1973.

$\rightarrow$ Telser, Lester G. "A Theory of Innovation and Its Effects." Bell J. Econ. 13 (Spring 1982): 69-92.

U.S. Department of Commerce, Patent and Trademark Office. General Information Concerning Patents. No. 003-004-00555-6. Washington: U.S. Government Printing Office, 1978.

U.S. Department of Commerce, Patent and Trademark Office, Office of Technology and Assessment. Reports, nos. 1-9. Washington, 1973-79.

von Hippel, Eric. "Appropriability of Innovation Benefit as a Predictor of the Source of Innovation.” Res. Policy 11 (April 1982): 95-115.

Wilson, Robert Woodrow. "The Sale of Technology through Licensing." Ph.D. dissertation, Yale Univ., 1975. 